\title{
Digital Firm: Requirements, Recommendations, and Evaluation the Success in Digitization
}

\author{
Yahya Al-Samawi \\ Computer Science Department, Al-Razi University, Sana'a, Yemen \\ E-mail: ysamawix@gmail.com
}

Received: 20 August 2018; Accepted: 22 September 2018; Published: 08 January 2019

\begin{abstract}
One of the most attractive goals for the contemporary companies is to be called a Digital Firm. Achieving this goal means for the company, university, school, factory or hospital that it is one of the most modern and developed in the world. To achieve such an attractive goal, firms have to fulfill some requirements. In this research paper, author introduces many important ideas about the characteristics that the digital firm has to have to deserve to be called digital. Those characteristics are followed by some recommendations about IT-tools that the firm can use to comply with a specific characteristic. Moreover, author introduces some questions that have to be answered to judge correctly about the level of firm's digitalization that will help evaluating the firm's success in digitization. This research is unique because it draws attention of the developers of the contemporary Information Systems (IS) to some aspects that are usually not taken into consideration such as the best characteristics of the elements of the workplace that is appropriate for the use of IT tools to help the users make less mistakes and gives the use of original software the importance that it deserves. In addition, it is important for many researchers nowadays who care about studying the contemporary IS and their usage in the contemporary firms to have knowledge about the main elements of IS that take into consideration all aspects of the Hardware, Software, workplace conditions and laws.
\end{abstract}

Index Terms-Digital Firm, Information Systems, Information Technology, IT tools, Digitization.

\section{INTRODUCTION}

There is no doubt that Information Technology (IT) became an essential part of the contemporary organizations. Managers of the modern companies understand more and more the importance of using new technologies to help achieving business goals in the best way. Organizations entered undeclared competition to use the newest IT tools and techniques to achieve competitive advantages. As a proof, the leader of the IT researches in the Gartner company expected that the worldwide IT spending will touch $\$ 3.5$ trillion in 2017 [1]. That led to the emergence of the term the Digital Firm (DF). The term
DF means in a simple way that the company runs its business totally with the help of IT tools. But, how managers and researchers can judge about the company that it deserves to be called digital? What the company has to do to become digital? In this research author gives answers to those questions giving the managers of the contemporary firms and IT professionals a proposal which contains guidelines about what they can do in their firms or IT projects to make the firm digital. The proposal consists of 13 requirements which have to be taken into consideration building IS of the firm. They are about elements of the IT infrastructure that have to be provided (hardware and Software) and the environment of the computer's workplace combined with rules that have to be followed building IS according to ethics and laws related to IT. The author also gives recommendations to help IS developers fulfil those requirements including better IT tools to fulfil basic tasks in the modern firms and recommendations about best characteristics of computer's workplace. The research article is concluded with a proposal of measurements to test firm's achievements in its way to be digital based on proposed requirements.

The goal of this research is to provide managers of the contemporary firms, IT professionals, IS developers and researchers with guidelines about the main components of the contemporary IS based on the contemporary studies in the field of IS development and needs. Those guidelines are introduced as requirements that have to be fulfilled by the contemporary IS to help the firm doing business better to get competitive advantage.

After the introduction the research is divided into 9 sections. In the next second section introduces the related to the research works. The third section provides the reader with a definition of the term DF and explains why it is important for the contemporary firms to do their best to be digital and use IT tools everywhere in the firm. The forth section contains explanations for the main characteristics provided by the author of [2] and why those characteristics need more decomposition and addition of more characteristics to describe DF better in the light of the contemporary studies of IT and humancomputer interaction. The fifth section introduces the proposed requirements of the DF. The sixth section offers recommendations to better fulfil proposed requirements. The seventh section provides the researchers and evaluators with proposal about how to evaluate the 
contemporary firm's success in digitization using questioners and investigating firms IS by a researcher or an evaluator. The eighth section had to introduce a case study as an experiment to show how the proposed requirements and evaluation process can help evaluating the firm's success in digitization but instead it contains an explanation about why there is no experiments because of the difficult situation caused by war in the country of the author. In the conclusion section the author shortly explained what he achieved with this research and why it is important to apply its results in the contemporary firms.

\section{RELATED WORK}

This research is based on several studies in the field of IS and IT tools and how to use them effectively by the contemporary firms to get the best competitive advantage. The main work is the work of [2] that introduces the term of DF and some of its characteristics and elements of the contemporary IS. Other works are related in some parts of this research as a source for recommendations of the IS elements and how to fulfil some requirements proposed in this research as in [16] which gives recommendations about the best characteristics of the computer workplace.

\section{DigITAL FIRM: DEFITION AND IMPORTANCE}

\section{A. Definition of the Digital Firm}

Based on [2] DF is the firm that runs all its important business processes connected to customers, suppliers and employees using IT tools. This is an excellent clear definition of the DF which comprises all main human components of the organization who needs the IT tools to run tasks. Employees, customers and suppliers need IT tools to help them achieve their goals dealing with the organization. This is the goal of the IT infrastructure of the contemporary organizations, to help human get their job done faster and better.

\section{B. The Importance of Being Digital}

It is of great importance for the contemporary firms to exploit full complex of advantages of the IT tools to survive nowadays. Firms that do not use IT tools to run business are going to be overcome by competitors. Companies that make use of IT tools do jobs faster with better quality than the firms which still have most of its jobs done using old paper- and hand-work. Following are some important tasks that IT tools help running faster and better based on [3]:

\section{Better communication}

The task of data transferring is a very important task in the modern organizations. Managers need data to be available in due time to make better decisions. Employees need to exchange information to help performing tasks better and faster. Customers need to have access to necessary data at any time anywhere. Suppliers may exist in far countries; as a result, they need remote access to organization's data that is related to products or services they provide. All those needs can be provided with high quality of service with the help of computer networks, Internet and many types of enterprise software.

\section{Better Operations Running}

Most of business processes if not all of them can be run very effectively with the help of IT tools. If the company makes the use of modern technological achievements to run its tasks, then it will get better performance. For example, selling can be done much faster than using the combination of the following IT tools: computers, barcode readers and Databases Systems. IT tools can be used to control all the processes needed for manufacturing to produce products of the best quality as fast as possible. Monitoring and control can be done very easy with the help of IT tools.

\section{Better Decision Making}

Managing is all about making decisions. To make better decisions manager has to have access to data in due time. Data must be gathered, processed, analyzed then represented in the best way to help managers make better decisions. All those tasks can be done with high level of quality and speed with the help of IT tools. The modern achievements in the field of Artificial Intelligence (AI) and Machine Learning (ML) provide contemporary firms with the best tools for analyzing data and discovering knowledge in the huge amount of data that modern firms have to deal with.

\section{Better Tools for Record-Keeping}

Companies need to keep all its data - current or historical - for long time to make it available for their employees at any time to provide them with knowledge and previous experiences that they need to correctly do job and make better decisions. Databases, Data Warehouses, Electronic Archiving Systems and various types of files that keep data in many useful structures and formats can fulfil this task much better than any old-fusion paper-based system.

As a result, all the contemporary companies need to pay more and more attention to the importance of using modern IT tools to run tasks faster with better quality to achieve competitive advantages.

\section{Characteristics of the Digital Firm}

Previously introduced sections show the importance of IT in modern business and motivate the modern firms to do their best to become DFs. But, there is a necessity to provide contemporary firms with more specific guidance that help their managers and IT professionals understand better what they need to do to make their firms digital and to know how much they success in that. The authors of [2] provide some characteristics of the digital firm that can be used to evaluate modern company's success in becoming digital. Following are four characteristics they marked for the DF followed by explaining how they can be achieved using IT tools: 
1. Managing all assets through digital means.

2. Availability of data at any time anywhere.

3. DF is flexible in the essence that it changes based on the changes in the business environment very quickly.

4. DF works effectively all the time (24/7 work mode) and anywhere.

The first characteristic is achieved by managing the firm in all levels of management using IT tools and techniques. Business processes have to run effectively using IT tools. DSS, MIS, EIS, TPS, CRMS, SCMS and ERP help in managing and running processes within the DF [4].

There are many IT tools to help achieving the second characteristic. Computer networks in combination with Central Data Storages tools such as SAN or servers with RAID technology that maintain firm's data in central Databases make the data available at any time anywhere in the company.

The use of IT tools makes the firm more flexible and able to change how it runs tasks any time business conditions change. Adding new entities, new employees, and new products is done easily when the firm manages and controls its business processes using IT tools. Robots that help making products can be reprogrammed easily to produce new products or improve production to keep up with changes in the clients' moods and preferences. Analytical intellectual systems can sense and discover patterns and anomalies in data rapidly to help making better informed decisions in due time to help changing business to face new challenges.

Modern Supercomputers and servers in combination with various techniques such as replication and automatization of many important tasks make the firm available in 24/7 work-mode. Making changes in work places anywhere in firms' branches can be done easily thanks to all previously mentioned tools and techniques.

All those characteristics are useful and very important in deciding if the firm has achieved this exciting goal of being digital, but there are many other characteristics that has to be taken into consideration in the way of being digital. The following sections are introducing those requirements based on author's opinion and knowledge.

\section{REQUIREMENTS TO BE DIGITAL FIRM}

First of all, it is hard to judge the firm saying that it is a $100 \%$ digital firm because there must be a place for human to do some job, at least as a supervisor over the system. But, there are many main components that the contemporary firm has to have and use to deserve to be called DF. Following, the author offers several important requirements that can be used to judge the firm's percentage of digitalization. These requirements are more detailed than previously introduced characteristics and cover more aspects that are really important to be fulfilled by the contemporary DFs.

\section{Firm's employees are digital.}

The term Digital Employee (DE) means that the employee himlherself has the following characteristics related to the use of IT tools:

\section{a. Helshe must have the basic knowledge of the IT tools}

Each employee of the firm has to have basic skills of using basic computer programs such as: operating systems (windows, Linux and android), text processors (such as MS Word), spreadsheet software (such as MS Excel), presentation software (such as MS Power Point) and the Internet software for browsing, email, file transferring and web searching for information that helshe may need for job. In short, how many employees have ICDL or its equivalent certificate? Besides, employee has to have basic knowledge of the computer organization such as: main components of computer and tablet hardware and their functions. If the firm discover an employee with no such certificate or skills it has to provide hemlher with needed training and skills.

\section{b. The DE uses IT tools for all the tasks helshe has to do.}

Everything that the employee has to do to fulfil his her tasks has to have specialized IT tools that help hemlher do it faster and better. The employee should almost never use pen and paper. Helshe must have special IT tools for data storage retrieval, analysis and reporting.

\section{c. DE has to be provided with all IT tools needed for job}

DE must have hisher own computer whether it is Desktop, laptop or tablet (in nowadays it is preferred for the employee to have Desktop for more possibilities and tablet for mobile work). Considering the fact that any employee usually needs to move to other employees or to managers to deliver some information helshe needs to discuss, employee must be provided with laptop or tablet. This must be provided by the firm itself not by the employee on histher own financial abilities. The employee has to be provided with other tools such as: flash memory, external HDDISSD, fast Internet connection, printer and scanner to be able to do doing job digitally.

\section{Supporting Digital Culture}

Using IT tools and knowing what IT tool to use when needed must be part of employees' life and traditions in the firm. To fulfill such goal, the firm must supply employees with high level of training, meetings, symposiums and instructions to get needed level of ITknowledge and have the usage of IT tools as a part of usual life. The employee and manager must think digitally. Digital thinking means that when helshe needs to do something, the first idea that comes to mind is to use appropriate IT tool.

\section{Using Digital Communications}

Communications must be done using IT tools such as: computer network as the main platform for communication in the DF, chat software, video conference 
tools, voice calls, emails, special web sites and profiles in popular social media cites must be provided to the employees, customers and suppliers so they can contact each other easily and timely. Customers and suppliers must have appropriate IT tools to contact the firm at anytime and anywhere.

\section{Fast knowledge of modern technologies}

Digital Firm has to provide employees with knowledge of the newest technologies and how they could be used to run tasks better. This will help the firm to be more competitive and never stay behind other competitors.

\section{Central Digital Data Storage}

The main goal of IS and IT tools, in general, is to help dealing with data. Data of the DF has to be stored in central IT tools for faster retrieval remotely by all employees, clients and suppliers. Servers that have Database with DBMS, File Server for shared documents and other files, and Data Warehouses for current and historical data for easy analysis are the main elements of the central data storage.

\section{Digital Archive}

Any firm has to have an archive where it stores its historical data: its documents, records, receipts, reports and so on. Paper archives are huge and difficult to be accessed in due time. DF has to use contemporary archiving systems which provide faster access and data retrieval with nice-looking GUI that is easy to use by all employees.

\section{Digital Library}

Employees in any firm need to develop their knowledge and experiences. They have to have all knowledge resources such as books, journals, and newspapers all next to them all the time. DF has to provide its employees with any all knowledge resources in digital form. It has to acquire all needed sources and support making such sources by its employees who has high level of experience. Paper books occupy big territory and consume big resources. DF has to provide its employees with digital library that is easy to search within and retrieve information at any time from anyplace in the firm. Meanwhile, the library must not break the law. Authors' rights must be preserved according to the law.

\section{Digital Help and Support}

When a client needs to know about the DF, its services, or the state of histher order helshe should not be compelled to travel far distances to enquire about that. Employee also, from time to time, would need fast access to help every time encounters trouble doing his her work or needs to know more about his her responsibilities. The firm must provide its clients with a web-site, profiles on social sites such as Facebook that show the client all the basic and detailed information helshe needs to know about the firm and its services. There must be digital help desk software to help employees and clients ask questions and get immediate answers that help them to solve any problems they would encounter with products, IT tools, services and so on.

\section{Original Software}

Firm that aims to be proud of being digital has to use only original legal Software. It has to comply with all the laws related to ownership rights. All the software in the DF's IS must be legal. No pirate copy of any small or big software is being used to do any tasks in the DF.

\section{Existence of Security Policy}

Firm that uses IT tools to run tasks has to care about Information Security. IT tools may become a source of anxiety and danger for the firm if they are not protected at an appropriate level. All measures must be taken to protect information from tended or untended threats caused by firm's adversaries. Each employee has to understand his her role in information security in the DF. Helshe has to know the level of security the data helshe deals with have, what vulnerabilities threaten them and how to protect them. Identification of employees has to be done using IT tools, starting at the entrance of the firm if such identification needed till the use of computers and accessing data in the data center.

\section{Existence of IT Department}

Having its tasks running fully with the help of IT tools, the DF must support IT infrastructure. Any failure must be dealt with in due time. For that, the DF must provide a specialized IT department that includes several IT specialists in the main IT professions, such as: computer engineer, network engineer, system analyst and others.

\section{Digital Intelligent Decision Making}

According to [5], creative decision making is among vital elements of the successful organization. Actually, it is all about decision making in the contemporary firms. The main goal of IS is to provide best tools and practices to deal with firm's data to make it available for managers, in the first place, to help them make better informed decisions. Accordingly, DF has to pay special attention to the process of making decisions using for that the best IT tools for decision support at all stages of the process of decision making.

Modern technologies provide firms with powerful tools that help making better decisions. Those tools undertake the most part of the process of making decisions including data gathering, data cleaning, data-analysis until the representation of the results in the best way that help the manager make better decisions. DF must use the most modern and powerful IT-tools that support decision making everywhere it needs them.

\section{Ergonomic IT Workplace}

Contemporary firms' managers may think that providing employees with the best computers and other IT tools is a guarantee of the best outcomes. They usually forget about the physical and psychological aspects of the Human Computer Interaction (HCI). Employees usually have to use IT tools for several hours a day. Building IS 
for the contemporary firms, the IS designer must not forget about employees' comfort. The IS must fulfill the known standards and recommendations for best ergonomic IT workplace. Such recommendations as: Ergonomic chairs, desks, computers, and light; better positioning of all IT infrastructure elements; using of noise suppression, having friendly GUI for software and so on. Ergonomic workplace makes the employees more productive making fewer mistakes [6]. As a proof for the importance of providing ergonomic workplace for employees, in the report to Congress the General Accounting Office presented case studies in which costs associated with cumulative trauma disorders (CTD's) were dramatically reduced when ergonomics programs were instituted [7].

The following figure shows shortly introduced requirements of the DF.

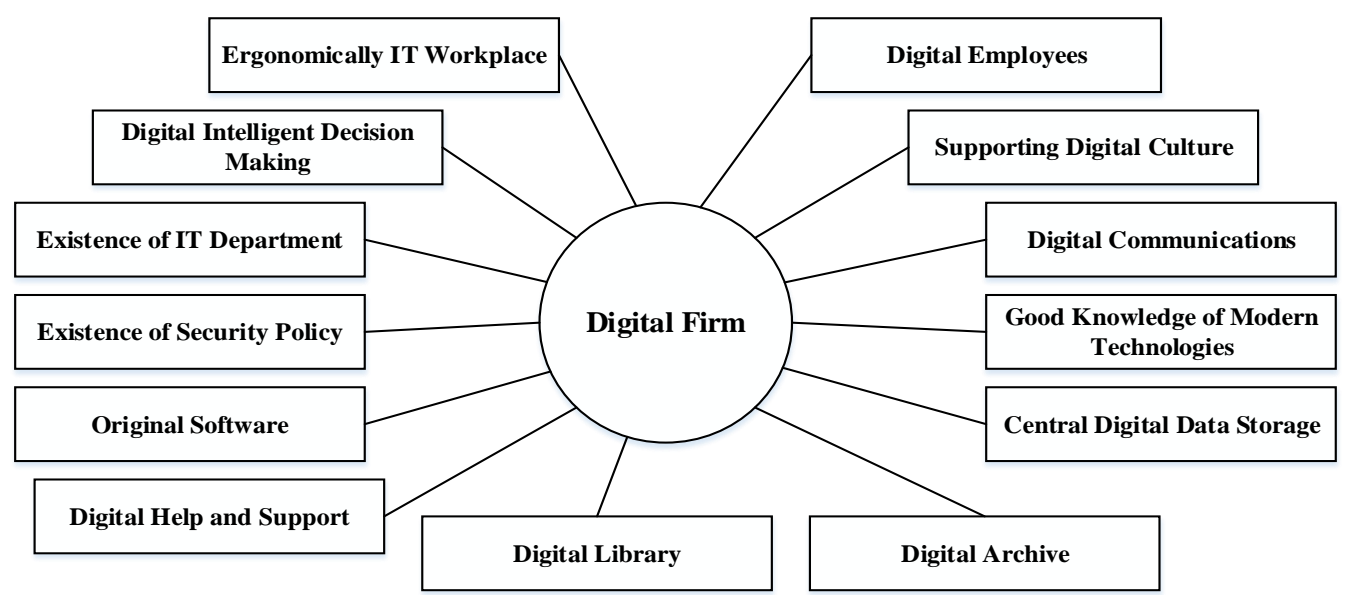

Fig.1. Digital Firm requirements

\section{RECOMMENDATIONS TO BE DIGITAL}

Following are some advices about various IT tools to realize previously introduced requirements of the DF.

\section{Digital employee}

a. Employee has to know how to use modern OSes. The most popular of them for an employee are Windows 7/8 for desktop computers and Android for Tablets. This knowledge must include: setting up characteristics of the desktop, dealing with folders and files, OS maintenance, running defragmentation task, formatting flash drives, changing user's account details such as user name, password and account picture. The use of MS Word including: text editing and formatting, dealing with images and tables, editing headers and footers, creating titles and table of contents, and protecting documents with passwords. The use of MS Excel including: formatting cells and tables, using basic formulas, creating different kinds of charts to represent statistics about different data. Creating nice-looking presentations with such program as Power Point including: dealing with slides, changing themes, formatting texts, adding appropriate SmartArt, using transitions, creating animations and managing slide show. It is really embarrassing when sometimes a presentation freezes while the employee or a manager is introducing an important project plan if helshe has to wait until tech-support come to fix it, meanwhile the solution is merely to press ctrl+alt+delete then stop the program in the task manager then restart it again to proceed.

b. Based on the tasks an employee has to do, he/she must know what technology to use and how to use it. For example, an employee needs to add a picture of the meeting to a report about the meeting but the picture is a little bit dark. He/she must know how to remove SD card memory from the digital camera, connect it to the computer using SD card reader, open the picture in any simple image processing program such as ACDsee or FastStone Image Viewer, then change the contrast and light as needed, save changes, then add it to the report in Word document. Another task is converting word document into PDF document, including merging many files if needed. Other tasks based on employee's job, also, have to be done with the help of IT tools.

c. The employee has to have all needed IT-tools to do tasks easily. Such tools as: Tablet, Smartphone, Internet Connection, remote access to data in Data Centers, USB flash memory for data exchange, printer, and scanner.

\section{Digital Culture}

Firm must provide employees with periodical training and sessions that make them acquaintance with IT-tools they can use to do tasks. It has to provide employees with all necessary tools. It may use posters on walls that remind with tools and their usage. As a result, employees will have the needed knowledge and skills to use IT tools all the time bringing digital culture to a high level in the DF. 


\section{Digital Communications}

All communications between the firm's employees, between the firm and customers or between the firm and its suppliers has to be made using IT techniques and tools. Computer networks connect all computers in the firm. The firm has to have special web-site for its needs. It has to create special profiles and groups in the most popular social media sites, such as Facebook. It has to create groups in such popular apps as WhatsApp for communication. All those tools are used to communicate necessary information to the employees, clients, suppliers and interested parties remotely. They are also used to get feedback, place orders, request information from interested parties. Special software must be used for collaboration and communications. Such software as: chat software, data transferring applications, virtual meeting software, voice and video conference software. The firm can have all these possibilities and services in one package in such software as MS SharePoint or IBM Lotus Notes. Employees' computers have to have all necessary tools for communication such as: web-camera, microphone, mobile internet access using $\mathrm{Wi}$-Fi access points every-where in the firm's buildings.

\section{Fast knowledge of modern technologies}

Firm has to provide its employees with the information about the most contemporary IT tools and techniques. Special sessions, trainings, seminars and symposiums have to be organized from time to time to give employees such knowledge.

\section{Having Central Digital Data Storage}

Data has to be stored using best data storage devices and organized using best software tools. Storage Area Network (SAN) is an appropriate technology for central data storage in big firms [8]. Relational Database Management Systems (RDBMS) are good enough for organizing structured data in the firm using for example Oracle Databases and DBMS. Special software for dealing with unstructured data can be used by firm's servers or the DF can use the services of the cloud that is better saves money and time in maintaining Big Data.

\section{Digital Archive}

As long as all the work in the DF is done by IT tools, archive must be digital and it has to be supplied with entries automatically. Documents and images of all firm's transactions and operations have to be inserted into the Enterprise Archiving System automatically. Friendly GUI helps managers and employees access archive easily. Contemporary firms can make use of modern Enterprise Archiving Systems such as: Symantec Enterprise Vault, EMC Source One archiving, Mime cast and so on [9].

\section{Digital Library}

No company can ignore the importance of experience and knowledge for employees. Knowledge from books, manual guidance, experts has to be available for all employees all the time. Digital library has to be provided and it has to be easy accessed. Firm can use one of the most popular Library Systems, such as: Lucidea Integrated Library Systems, Mandarin M5 and Insignia Library System [10].

\section{Digital Help and Support}

DF has to provide special electronic Helpdesk that provides customers with the help and answers they need. It also has to provide employees with all needed information about IS components, employees and their responsibilities, the roles that govern the DF, and how the system works. DF can build such systems with the functions it needs or it can use third-party software such as software provided by [11]: LiveAgent, Vision Helpdesk, ServiceDesk Plus and so on.

\section{Using Original Software}

DF has several options to choose from building its IS to comply with ownership rights. Based on [8] those options are:

\section{a. Using Original Retail Software.}

This option is usually expensive, but provides DF with well-known and tested software from respectful and trusted companies of software engineering which have high level of experience in this field. Windows operating systems and MS Office applications, SAP systems, and MS SharePoint are examples of such software.

\section{b. Building its own software}

This option provides DF with good software that is built and suited to its needs. They maybe cheaper than original solutions from third party, but such solutions usually are developed too slowly and hard to be maintained and updated in the future if changed happened to firm's programmers.

\section{c. Using freeware}

In the recent time there are myriad amount of freeware that are built by groups of software developers who request no money for their work. Examples of such software are various distributives of Linux OS, Apache OpenOffice and much other free software.

It is recommended for the contemporary firms to use a mix of all the three solutions. For example: DF can install and use retail software for critical tasks such as: managing workstations and servers (Windows, Macintosh, or Redhat operating systems), managing IS data resources (Oracle DBMS), and for managing main business processes (CRM, SCM and Financial Affairs Systems from such companies as SAP, Oracle, or Microsoft). Meanwhile, DF can use freeware for simple tasks such as: document processing (Open Office), collaboration systems (Dropbox, Google Docs, Slack [12]), Calendars, Timers and so on. Besides, DF can develop its own software for such tasks as archiving, Library management systems, and Help Desk Systems.

\section{Existence of Security Policy}

Every computer in the DF must have at least a Firewall 
and Antivirus software. These programs must be kept upgraded. Sensitive data must be protected using all necessary means: encryption and access rights control that are protected with authentication process. Digital Signature is used instead of usual signature as an identification technique for documents. Access is controlled using digital technique such as fingerprint scanners to identify each employee.

The most important, the DF must have a clear wellorganized Security Policy. As [13] define Security Policy, it is measures that are taken by the firm to protect its system resources based on rules created to manage the information security in it. To comply with this requirement DF has to have Security policy that clearly explains the following six elements for each employee based of the model introduced also in [13]:

1. Assets: components that have value for the owners.

2. Owners: persons who valuate assets and need to impose countermeasures to protect assets from threads.

3. Countermeasures: procedures and tools to protect information.

4. Risk: vulnerabilities in the system that may threaten the assets.

5. Threats: Violation of security that may harm assets.

6. Adversary: a person who may attack the system to gain illegal access to its resources.

All employees must have controlled data access based on their roles and responsibilities. They must know their rights on data and IS components according to the Security Policy.

\section{Existence of IT Department}

The DF must provide a specialized IT department that includes several IT specialists in the main IT professions which are based on [14]: software engineer, computer systems administrator, computer support specialist, information security analyst, Database Administrator (DBA), Computer Network Architect, Web Developer, and IT Manager. In general, the DF has to have an IT department that must have at least a computer engineer, network engineer and a system analyst to help discovering problems, analyzing them and offer IT technique to deal with it.

\section{Digital Intelligent Decision Making}

DF must use the most modern and powerful IT-tools that are made to support better decision making everywhere it needs them. Such tools as: SAP BusinessObjects, QlikView, TIBCO Spotfire and so on [15].

\section{Ergonomic workplace suited for IT tools usage}

Ergonomic workplace for computer use includes: ergonomic chair and desk, appropriate light for the whole workplace, best hardware appropriate for fulfilling tasks, and software with the best GUI which is made taking into the consideration HCI rules and recommendations. Following are some recommendations for ergonomic workplace suited for the use of computers [16]:

$>$ The monitor at the height of the head.

$>$ Thighs are parallel to the floor.

$>$ The chair has to be adjustable.

Area lighting levels from 300 to 500 lux.

Besides, DF has to organize periodical trainings and sessions to make employees aware of health problems that they may encounter using IT tools. Instructions for better ergonomic workplace must be kept in visible places where each employee can notice them to remind them all the time about better work conditions and behaviors.

In conclusion to this part, the following table summarizes the recommendations for each previously stated characteristic of DF.

Table 1. Characteristics of the DF and suggestions for IT tools

\begin{tabular}{|c|c|l|}
\hline $\mathbf{N}$ & Characteristic & \multicolumn{1}{c|}{ Recommendation } \\
\hline 1. & Digital employee & $\begin{array}{l}\text { Having at least knowledge of how to use MS Windows, Android, MS Office, Internet, E-mail software } \\
\text { Runs all tasks using IT tools } \\
\text { Has all IT tools for portable and easy work: flash Memory, external HDD or SSD, tablet, workstation, } \\
\text { printer, computer, and fast access to the Internet }\end{array}$ \\
\hline 2. & Digital Culture & Periodical training and sessions about IT Tools and how to use them \\
\hline 3. & Digital Communications & $\begin{array}{l}\text { Computer Network, Internet Access, Collaboration Software (MS SharePoint or IBM Lotus Notes or } \\
\text { any other programs as needed) }\end{array}$ \\
\hline 4. & $\begin{array}{c}\text { Fast knowledge of modern } \\
\text { technologies }\end{array}$ & Organizing Sessions, trainings, seminars and symposiums about new technologies \\
\hline 5. & $\begin{array}{c}\text { Has Central Digital Data } \\
\text { Storage }\end{array}$ & Data Centers, SAN or RAID \\
\hline 6. & Digital Archive & Symantec Enterprise Vault, EMC SourceOne archiving or Mimecast \\
\hline 7. & Digital Library & Lucidea Integrated Library Systems, Mandarin M5 or Insignia Library System \\
\hline 8. & Digital Help and Support & LiveAgent, Vision Helpdesk, ServiceDesk Plus \\
\hline 9. & Using Original Software & $\begin{array}{l}\text { Retail OS: Windows for workstation or for servers, MS Office. } \\
\text { Freeware: Ubuntu OS, Open Office, and other freeware to form free IS. }\end{array}$ \\
\hline 10. & Existence of Security Policy & Using the model introduced in [6] to build security policy \\
\hline 11. & $\begin{array}{c}\text { Digital Intelligent Decision } \\
\text { Making }\end{array}$ & SAP BusinessObjects, QlikView, TIBCO Spotfire \\
\hline 12. & $\begin{array}{c}\text { Ergonomic workplace suited } \\
\text { for IT tools usage }\end{array}$ & Ergonomic chair, desk, computer positioning, light, sound suppression \\
\hline 13. & Existence of IT Department & At least Computer engineer, Network engineer, DBA \\
\hline
\end{tabular}




\section{EVALUATION}

It is important to know how to measure previously introduced characteristics to make informed decision about the firm's success in digitization. This part introduces questions which has to be answered with explanations how to evaluate their answers. However, before introducing those questions, it is important to pay attention to the fact that some requirements are essential and without fulfilling them, the firm does not deserve to call itself digital. Among the introduced requirements there is one requirement that if not satisfied the whole complex of requirements are neglected even if they are all provided. This requirement is: the firm has to use only original software that does not break the laws of ownership rights. The main formula is as following:

$$
D F=\sum_{i=1}^{12} r_{i} \times O S
$$

Where DF a variable which keeps the value that represent the success of the firm in digitization; DF <= maximum value calculated based on IT components considered in the study and is equivalent to the value <= $100 \% . r_{i}$ are variables that contain the value of every requirement; $i=1 . .12$. OS stands for Original Software, variable that has the value 0 or 1 for the original software requirement. It is multiplied by the sum of all percent of all other 12 variables in such way that it brings them all to 0 if the value is 0 if the firm uses any illegal software.

\section{Digital employee}

For the characteristics of the digital employee as introduced earlier there are three main characteristics. The following sample of a questionnaire that a sample of firm's employees has to answer to is presented in figure 2.

\section{Digital Culture}

A simple question about having periodical trainings and sessions on IT tools that gives the answer yes or no will be sufficient. Figure 3 shows a questionnaire for checking this requirement.

\section{Digital Employee}

Please answer the following questions unbiasedly and honestly

\begin{tabular}{|c|c|c|c|c|c|c|}
\hline \multirow{3}{*}{ Knowledge of IT tools } & \multicolumn{3}{|c|}{ Knowledge, $\mathrm{K}$} & \multicolumn{2}{|c|}{ Training, $T$} & \multirow{2}{*}{$\begin{array}{c}\text { Mark } \\
\mathrm{K} * \mathrm{~T}\end{array}$} \\
\hline & No & Part & All & Self & Firm & \\
\hline & 0 & 1 & 2 & 1 & 2 & Max $=4$ \\
\hline \multicolumn{7}{|l|}{$\begin{array}{l}\text { Using Windows OS: Working with Desktop, changing Background } \\
\text { Image, Folders, Flash Formatting, installingluninstalling applications }\end{array}$} \\
\hline \multicolumn{7}{|l|}{$\begin{array}{l}\text { Using Android: Working with Desktop, changing Background Image, } \\
\text { Folders, Flash Formatting, Apps installation and deletion }\end{array}$} \\
\hline \multicolumn{7}{|l|}{$\begin{array}{l}\text { Using MS Word: menu elements, text formatting, Image and table } \\
\text { processing, Paragraph, Page formatting, parameters setting }\end{array}$} \\
\hline \multicolumn{7}{|l|}{$\begin{array}{l}\text { Adobe Photoshop: simple image processing, selection, coloring, } \\
\text { cropping, using effects }\end{array}$} \\
\hline \multicolumn{7}{|l|}{$\begin{array}{l}\text { Basic Hardware Knowledge: main elements of computer hardware, } \\
\text { functions and differences of HDD, SSD, Flash Memory, CPU, and RAM }\end{array}$} \\
\hline \multicolumn{7}{|l|}{$\begin{array}{l}\text { Basic Knowledge of Databases: creating tables, forms, queries and } \\
\text { reports in MS Access, making quires }\end{array}$} \\
\hline \multicolumn{7}{|l|}{$\begin{array}{l}\text { Internet: opening web-pages, sending e-mails, searching for data with } \\
\text { search engine, downloading images and eBooks and PDF files, creating } \\
\text { profiles in web-sites, using downloaders }\end{array}$} \\
\hline \multicolumn{6}{|c|}{ The Average } & \\
\hline
\end{tabular}

\begin{tabular}{|c|c|c|c|c|c|c|c|c|}
\hline \multirow{3}{*}{ Running tasks using IT tools } & \multirow{2}{*}{$\begin{array}{l}\text { Computer } \\
\text { Aided, CA }\end{array}$} & \multirow{2}{*}{$\begin{array}{c}\text { Hand } \\
\text { work, } \mathrm{H}\end{array}$} & \multicolumn{5}{|c|}{ Satisfaction, Sat } & \multirow{2}{*}{$\begin{array}{c}\text { Mark } \\
\text { CA } \backslash H^{*} \text { Sat }\end{array}$} \\
\hline & & & No & Weak & Good & VG & Excel. & \\
\hline & 1 & 0 & 1 & 2 & 3 & 4 & 5 & Max $=5$ \\
\hline \multicolumn{9}{|l|}{ Task 1} \\
\hline \multicolumn{9}{|l|}{ Task 2} \\
\hline \multicolumn{9}{|l|}{ Task $n$} \\
\hline & & & & & & The & Average & \\
\hline
\end{tabular}

\begin{tabular}{|c|c|c|c|c|c|c|c|c|c|c|c|}
\hline \multirow{3}{*}{\multicolumn{2}{|c|}{ Provided with needed IT tools }} & \multicolumn{2}{|c|}{ Existence, $\mathrm{E}$} & \multicolumn{2}{|c|}{ Source, $\mathrm{Sr}$} & \multicolumn{5}{|c|}{ Satisfaction, Sat } & \multirow{3}{*}{$\begin{array}{c}\text { Mark } \\
\mathrm{E}^{*} \mathrm{Sr}{ }^{*} \text { Sat } \\
\text { Max }=10\end{array}$} \\
\hline & & \multirow{2}{*}{$\begin{array}{c}\text { No } \\
0\end{array}$} & \multirow{2}{*}{$\begin{array}{c}\text { Yes } \\
1\end{array}$} & \multirow{2}{*}{$\begin{array}{c}\text { Firm } \\
1\end{array}$} & \multirow{2}{*}{$\begin{array}{c}\text { Self } \\
2\end{array}$} & \multirow{2}{*}{\begin{tabular}{c|} 
No \\
1 \\
\end{tabular}} & \multirow{2}{*}{$\begin{array}{c}\text { Weak } \\
2\end{array}$} & \multirow{2}{*}{$\begin{array}{c}\text { Good } \\
3 \\
\end{array}$} & \multirow{2}{*}{$\begin{array}{c}\text { VG } \\
4\end{array}$} & \multirow{2}{*}{$\begin{array}{c}\text { Excel. } \\
5\end{array}$} & \\
\hline & & & & & & & & & & & \\
\hline 1. & Desktop or Laptop & & & & & & & & & & \\
\hline 2. & Tablet & & & & & & & & & & \\
\hline 3. & Flash Memory & & & & & & & & & & \\
\hline 4. & External HDD/SSD & & & & & & & & & & \\
\hline 5. & Internet Connection & & & & & & & & & & \\
\hline 6. & Printer and Scanner & & & & & & & & & & \\
\hline & & & & & & & & & The A & verage & \\
\hline
\end{tabular}

Fig.2. Sample of a questionnaire for Digital Employee requirement evaluation 


\section{Digital Culture}

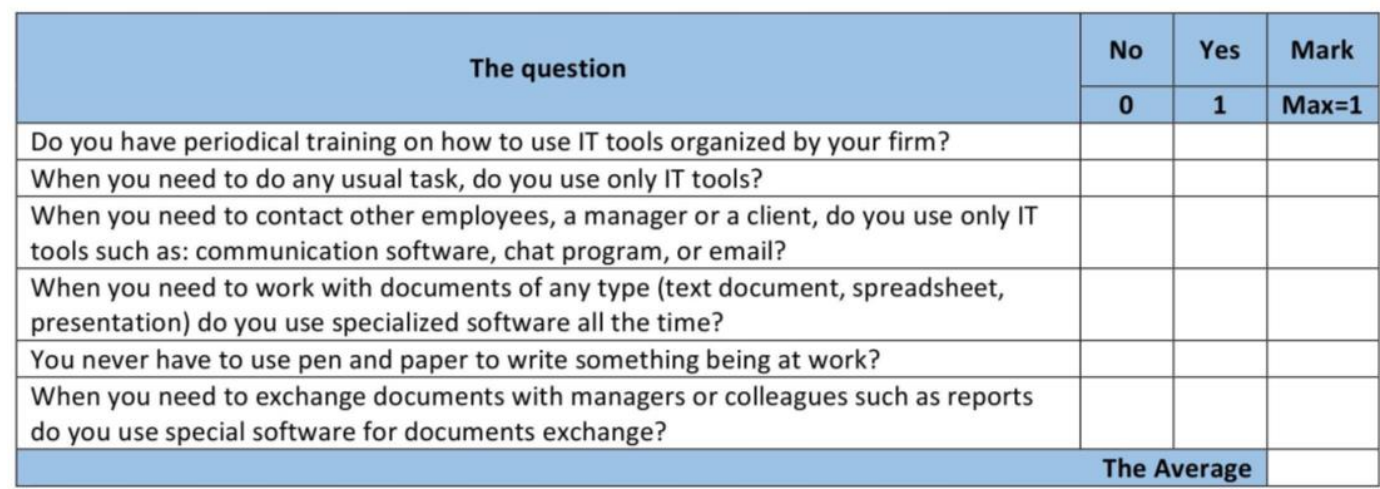

Fig.3. Evaluating the Digital Culture requirement

\section{Digital Communications}

Asking the following questions that give the answer yes or no can help measuring the achievements in this requirement. Those questions can be asked to the IS manager. Such questions as:

Does the firm have a computer network?

$>$ Does the firm have special web-site?

$>$ Does the firm have special profiles in popular social web-sites: Facebook, Twitter or WhatsApp for communication with customers and employees?

$>$ Does the firm have collaboration Software for communication and documents exchange such as MS SharePoint?

$>$ Does the firm provide each employee with webcamera, microphone, and mobile internet access for remote communications?

$>$ Does the firm organize virtual meeting using IT tools?

\section{Fast knowledge of modern technologies}

A simple question about having periodical trainings and sessions on the most contemporary IT tools that gives the answer yes or no will be sufficient.

\section{Having Central Digital Data Storage}

The evaluator can ask the managers or system administrator about the existence of Central Digital Data Storage. The Yes or "No" answer gives the needed value for evaluation. But, helshe also has to add a question about satisfaction of the IT tool in hands.

\section{Digital Archive}

As with the previous requirement, a simple question such as "Does the firm have software as an archiving system? Yes/No" will suffice. There also has to be question about satisfaction.

\section{Digital Library}

The evaluator can ask the following questions:

$>$ When you need to back to others' knowledge or experiences, do you use for that a software that allow you to ask experts and they give you answers online?

$>$ When you need to know more about any task you have to do, can you find a book or an explanation you need using a special software that does the work of digital library? Yes/No

Evaluator, as before, has to care about satisfaction of the available IT tool.

\section{Digital Help and Support}

The following questions can give needed values for evaluation:

$>$ When you encounter a problem at work, do you have the ability to contact help desk using special software? Yes/No

$>$ Does the help desk always give you answers that you need? Yes/No

$>$ Can you find all information about the firm, employees, jobs descriptions, and services in that help desk? Yes/No

\section{Using Original Software}

The following question that has to be asked for the IS manager then checked will give needed value for evaluation: Do the computers in the firm uses any pirate copies in any device in the firm's IS? Yes/No

\section{Existence of Security Policy}

This requirement requires few questions must be asked to the employee him/herself as following:

$>$ Does the firm have security policy? Yes/No

$>$ Do you have guidance about information security in your workplace? Yes/No

$>$ Do you have an Antivirus and a Firewall software installed on your computer? Yes/No

$>$ Are your firewall and anti-virus software updated and upgraded periodically? Yes/No

$>$ Do you need to login to your computer and data resources using user name and a password? Yes/No

$>$ Does the IS software provide you with tools to use Digital Signature when you exchange documents with colleagues? Yes/No

$>$ Do you know the elements of security policy that 
concerns your work (threats and protection)? Yes/No

$>$ Does the firm provide you with periodical training and sessions about the information security and Security Policy? Yes/no

$>$ Do you have electronic surveillance system the records everything and archive it for the future use? Yes/No

After asking questions the evaluator can use the following formula to evaluate the firm's achievement in providing high level of information security: Percentage of Information Security Achievement = the amount of Yes answers / the number of questions $* 100$.

\section{Existence of the IT department?}

For this requirement the following questions to the manager of IS will help in the evaluations:

$>$ Do the firm have special IT department? Yes/No

$>$ Which professions does the IT department have: Software engineer, computer systems administrator, Computer support specialist, information security analyst, DBA, Computer Network Architect, Web Developer, IT Manager. The evaluator has to decide which professions are essential for the firm based on its functions.

For the second question the evaluator has to consider the answer yes if the IT department has at least the following specialists: computer systems administrator, Computer support specialist, information security analyst, DBA, and Computer Network Architect, because those profusions are essential for the contemporary firms. Others can be provided by special software developing companies.

\section{Digital Intelligent Decision Making}

The following questions have to be given to the managers and system administrator.

Do you have DSS to do the job of data analysis and reporting for decision making? Yes/No

Another question can be asked also such as:

$>$ Do you have analyzing system that uses data mining techniques? Yes/no

$>$ Can your system create reports of the type Cube using ALAP systems? Yes/no

$>$ Do your executives have Digital Dashboards to show them clearly the current state of the business? Yes/No

\section{Ergonomic workplace suited for IT tools usage}

To measure this requirement, the tester has to check by himlherself the existence of ergonomic furniture suited for IT user. Based on [7], the main components of such environment are the following: workstation layout (Keyboard, the mouse and other input devices, monitor) ergonomic seating, desks, lighting. The existence of the recommendations introduced in the Recommendation part of this paper can be used for the evaluation of this requirement.

The evaluator can give the mark 1 for each complied requirement for each employee then calculates the percentage for each employee's work conditions as following: The percentage of ergonomic work environment $=$ the number of conditions fulfilled $/$ the number of conditions have to be fulfilled $* 100$. Later the evaluator can calculate the summary percentage for all employees using the following formula: Percentage of the fulfillment of the requirement $=$ the sum of all percentage of the requirement for each employee / the number of employees * 100. DF has to have $100 \%$ of this requirement's evaluation value.

\section{CASE STUDY}

Author tried to experiment with proposed requirements and evaluation questions on some firms in Yemen, but there were some problems aroused because that there is always some illegal software installed by employee himself/herself or by IT professionals of the firm what brings all firm's effort on digitization to zero based on the methodology of evaluation proposed by the author. Because of that the author cannot offer study cases to not harm any specific firm's reputation, especially with the fact that research is made in the time of war that causes many economic difficulties to all firms in the country. The war affected negatively the dollar cost that grows too high which in turn makes the cost of using only original software too high. Author hopes that situation is going to be better for this research to be a basis for enforcing high standards to be fulfilled by the contemporary firms in Yemen and in the whole world what will give stimuli to local firms to follow them to fighting even against piracy.

\section{CONCLUSION}

Nowadays, it is essential for the contemporary firm to get the full advantages of IT tools to help it run business faster and better. Moreover, it is prestigious for it to do its best to be fully digital which means that it runs all tasks using IT tools which means in its turn that it is the most modern. Achieving this goal, the firm can call itself a Digital Firm which is a great achievement based on the current importance and the great role of IT and IS in the success of the contemporary organizations. In this research paper the author provided managers of the contemporary firms, researchers and IT or IS specialists with important information about how to achieve such fascinating. The author introduced several requirements to be considered and fulfilled by the contemporary firm to be digital. He also provided the firm's managers and IS specialists with suggestions about how to fulfil those requirements. Moreover, he gave the researchers guidelines of how to evaluate contemporary firms' achievements in the process of digitization. 


\section{REFERENCES}

[1] Gartner (2017). Gartner Says Worldwide IT Spending Forecast to Grow 2.7 Percent in 2017. https://www.gartner.com/newsroom/id/3568917

[2] K. C. Laudon, J. P. Laudon (2012). Management Information Systems - Managing the digital firm, $13^{\text {th }}$ Edition Global Edition. Pearson. USA

[3] B. Markgraf (2018). Importance of Information Systems in an Organization, http://smallbusiness.chron.com/importance-informationsystems-organization-69529.html

[4] K. E. Pearlson, C. S. Saunders (2013). Managing and Using Information Systems, A Strategic Approach. John Wiley \& Sons, Inc.

[5] N. O. Ejimabo (2015). "The Influence of decision making in organizational leadership and management activities", Journal of Entrepreneurship \& Organization Management. USA, V4, issue2

[6] S. Mackenzie (2013). Human-Computer Interaction: An Empirical Research Perspective. Morgan Kaufmann, Elsevier. USA.

[7] Environmental Health and Safety. Ergonomics. Iowa State University, https://www.ehs.iastate.edu/occupational/ergonomics

[8] Y. A. Al-Samawi (2016). IT Infrastructure for Business Information Systems. IJCIT. Volume 05 - Issue 06. pp. 548- 555

[9] Drew Robb (2014). Data Archiving Buying Guide, http://www.enterprisestorageforum.com/backuprecovery/data-archiving-buying-guide.html

[10] Capterra (2018). Library Automation Software. https://www.capterra.com/library-automation-software/

[11] Capterra (2018). Help Desk Software. https://www.capterra.com/help-desk-software/

[12] Daniel Bulygin (2016), 7 Free Easy-to-Use Online Collaboration Tools - Make Teamwork Simple, https://trendblog.net/6-easy-to-use-online-collaborationtools-make-teamwork-simple/

[13] W. Stallings, L. Brown (2014). Computer Security: Principles and Practice (3rd Edition). Pearson. USA

[14] S. Snider (2017), Discover the 10 Best Technology Jobs of 2017, U.S.News, https://money.usnews.com/money/careers/slideshows/disc over-the-10-best-technology-jobs-of-2017

[15] Capterra (2018). Decision Support Software. https://www.capterra.com/decision-support-software/

[16] Ministry of Labour, Computer Ergonomics: Workstation Layout and Lighting, Canada, www.labour.gov.on.ca

\section{Authors' Profiles}

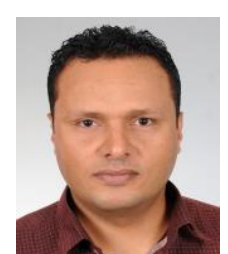

Yahya Al-Samawi received his $\mathrm{PhD}$ in System Analysis, Informaion Processing and Management in 2010. Currently, he is an assistant professor and the head of the Computer Science Department at Al-Razi University. His area of interest is the Information Systems, their development and developing IT tools to automate various tasks for the contemporary firms.

How to cite this paper: Yahya Al-Samawi, "Digital Firm: Requirements, Recommendations, and Evaluation the Success in Digitization", International Journal of Information Technology and Computer Science(IJITCS), Vol.11, No.1, pp.39-49, 2019. DOI: 10.5815/ijitcs.2019.01.05 